\title{
Shifting paradigms in coastal restoration: six decades' lessons
}

\section{from China}

Zezheng Liu, Baoshan Cui*, and Qiang He

School of Environment, State Key Laboratory of Water Environment Simulation, Beijing Normal University, Beijing 100875, China

Current address: Qiang He, Division of Marine Science and Conservation, Nicholas School of the Environment, Duke University, Duke Marine Lab Road, Beaufort, NC 28516, USA

* Correspondence: Baoshan Cui. Email: cuibs@bnu.edu.cn 


\begin{abstract}
With accelerating degradation of coastal environment worldwide, restoration has been elevated as a global strategy to enhance the functioning and social services of coastal ecosystems. While many developing countries suffer from intense coastal degradation, current understanding of the science and practice of their coastal restorations is extremely limited. Based on analysis of > 1000 restoration projects, we provide the first synthesis of China's coastal restorations. We show that China's coastal restoration has recently entered a rapidly developing stage, with an increasing number of restoration projects carried out in multiple types of coastal ecosystems. While long-term, national-level restorations enforced by the government appear promising for some coastal ecosystems, especially mangroves, restorations of many other coastal ecosystems, such as salt marshes, seagrasses and coral reefs, have been much less implemented, likely due to under-appreciation of their ecosystem services values. Furthermore, the planning, techniques, research/assessment, and participation models underlying current restorations remain largely inadequate for restoration to effectively halt rapid coastal degradation. To promote success, we propose a framework where paradigms in current restorations from planning to implementation and assessment are transformed in multiple ways. Our study has broad implications for coastal environmental management policies and practices, and should inform sustainable development of coupled human-ocean systems in many countries.
\end{abstract}

Key words: coastal environment, conservation strategies, ecosystem management, restoration policies and practices, China's coastal ecosystems 


\section{INTRODUCTION}

A most concerned environmental problem globally is degradation of coastal ecosystems such as salt marshes, mangroves, and coral reefs (Lotze et al., 2006; He et al., 2014). Coastal ecosystems are among the most valuable on Earth, due to their provisioning of diverse social services (e.g., storm/ tsunami protection and pollutant purification) for many of the worlds' societies, megacities and economic centers that are often located on the coast (Barbier et al., 2011). However, induced by population pressure, overexploitation, and global change, coastal ecosystems worldwide are severely degraded (Lotze et al., 2006; He et al., 2014; Sun et al., 2015). Approximately $50 \%$ of the world's salt marshes, $\sim 35 \%$ of mangroves, $\sim 29 \%$ of seagrass beds, and $\sim 30 \%$ of coral reefs have been lost or degraded (Barbier et al., 2008; Waycott et al., 2009). Coastal degradations have been even more dramatic in densely populated and rapidly developing regions including East Asia (He et al., 2014). As revealed in a recent survey by China State Oceanic Administration (SOA), China's salt marshes and mudflats have decreased by $57 \%$, mangroves by $73 \%$, and coral reefs by $80 \%$ since the 1950 s (Qiu, 2012).

Given the alarming condition of coastal ecosystems, substantial efforts have been made for protection, restoration, and sustainable use by governmental and private sectors around the world (Zedler, 2000; Bayraktarov et al., 2015). Importantly, restoration has been increasingly elevated for coastal conservation (Benayas et al., 2009). Restoration is an intentional activity that initiates or accelerates the recovery of a degraded or destroyed ecosystem (see Society for Ecological Restoration http://www.ser.org/), either by reintroducing target species, removing invasive species or constructing artificial habitats, or by removing or minimizing an environmental stressor, such as berm/dike blocking tides, to allow the ecosystem to reestablish on its own. There have been large coastal restoration programs in the Netherlands 
(De Jonge and De Jong, 2002), U.K. (Foster et al., 2013), Denmark (Morsing et al., 2013), and many other coastal countries in Europe. In North America, similarly, extensive restoration programs have been implemented to restore coastal wetlands in the Florida Everglades, Mississippi River Delta and Delaware Bay (see NOAA habitat conservation, USA, http://www.habitat.noaa.gov/restoration/restorationatlas/index.html). There are also a growing number of coastal restoration projects conducted in Australia (Laegdsgaard, 2006; Lotze et al., 2006).

As one of the countries that suffer from most severe coastal environmental deterioration, China has increasingly adopted restoration to improve or enhance coastal environments in recent years (Cui et al., 2009; Chen et al., 2012). Both central and local governments are substantially increasing investment for coastal restoration over the last few decades, and tens and hundreds of restoration projects are launched per year. Some of those projects have been suggested to effectively improve the status of coastal ecosystems (e.g., Cui et al., 2009). However, there are also rising concerns, and mixed successes or barriers for success have been indicated in multiple previous studies (e.g., Chen et al., 2009; Chen et al., 2012; Li et al., 2015). Importantly, despite the fact that hundreds of coastal restoration projects in multiple coastal ecosystems are carried out per year in China, past studies or reviews have often focused on one or a few projects or a specific restoration technique or ecosystem (e.g., mangrove planting). A broad, synthetic understanding of the mounting coastal restoration practices in China remains unavailable, and there are currently no studies that systematically examine the science, practices, and development progress of China's coastal restoration. Such a synthetic understanding, nevertheless, is not only of paramount importance to the success of future coastal restorations in China, but can also provide valuable lessons for many other coastal countries that suffer from intense coastal degradation (McKinnon et al., 2015). 
To provide such a broad, synthetic understanding, here, we conduct a systematic synthesis of China's coastal restorations that include projects conducted from the 1950s to date in tidal marshes, mangroves, seagrasses, coral reefs, sandy beaches, and coastal waters. We build a comprehensive dataset of 1011 coastal restoration projects reported in the primary literature, online news articles, and project reports. Using this dataset, we ask the questions of what is the development history of China's coastal restorations and what are the status and methods of different types of coastal restorations. Further, we identify existing issues that compromise current restoration efforts, from restoration planning to restoration methodologies to participation models, and propose potential solutions. To conclude, we provide a general framework for improving future efforts and advancing coastal restorations in China and many other coastal countries.

\section{OVERVIEW OF CHINA'S COASTAL RESTORATIONS}

Our comprehensive search for coastal restoration projects in China yielded in total 1011 projects (see Supplementary Information for data collection methods and the dataset).

Restorations have been conducted for most major coastal ecosystems present in China, including tidal marshes $(n=125)$, mangroves $(n=364)$, seagrasses $(n=11)$, coral reefs $(n=$ 12), sandy beaches $(n=88)$, coastal waters $(n=428)$, and others (e.g., oyster reefs; $n=18)$.

There have been three distinct stages in China's coastal restoration between the 1950s and present. At the first stage (before the 1980s), coastal restoration remained generally uninitiated (Fig. 1), except in a few places where mangroves were planted to rehabilitate bare mudflats - some of the earliest coastal restorations in China. The second stage was between the early 1980s and the late 1990s, during which a number of restorations were carried out, 
though they were primarily mangrove and coastal waters restorations (Fig. 1). The number of restoration projects per year fluctuated during this period, and restorations were discontinued in the late 1980s, likely due to a lack of funding (Yang, 2007). The third stage started from the early 2000s, when restorations of different types of coastal ecosystems, including tidal marshes, sandy beaches, seagrasses, and coral reefs, were launched, and the total number of restoration projects conducted per year has increased linearly (Fig. 1).

The rapid development of coastal restoration in China since the early 2000s is likely driven by the establishment of environmental protection regulations/policies and increasing governmental investment since the 2000s. Notably, in the early 2000s, the Chinese government approved a couple of national restoration programs (e.g., the National Wetland Conservation Program 2002-2030). These national-level policies stimulated significant governmental investment in coastal restoration. To date, the Chinese government has invested a total of 21.9 billion RMB for wetland restoration, and launched a variety of coastal restoration projects (State Forestry Administration, 2014). Most recently, in 2010, the Chinese government approved another environmental protection act, namely the Sea Area Utilization Payment Act. This Act requires ecological compensation from commercial use of seas, and the resulting funds are then invested into coastal restoration. In total 9.29 billion RMB of funds from this Act has been invested in restoring 5,876 ha of coastal ecosystems (State Oceanic Administration, 2014).

To date, coastal restoration has been carried out in all of China's 11 coastal provinces and four seas (Fig. 2a). Restorations of tidal marshes, mangroves, sandy beaches, and coastal waters spread out across their entire natural distribution range (Fig. 2b-g). Restorations of seagrasses and coral reefs, however, have concentrated in only two regions. While seagrass 
degradation has been reported in nearly all of the coastal provinces where they naturally occur (Zheng et al., 2013), seagrass restorations have been mainly concentrated in the Shandong peninsula and Guangxi province (Fig. 2d). Similarly, although coral reefs are lost to human impacts across southern coastal China (Fu et al., 2009), restorations have been carried out mainly in Sanya and Paracel islands in Hainan, and in Xuwen and Daya Bay in Guangdong (Fig. 2e).

\section{MAJOR ECOSYSTEM TYPES AND RESTORATIONS}

\subsection{Tidal marsh restoration}

China had expansive tidal marshes, mostly distributed in estuaries (the Yangtze, Yellow, and Liao Estuaries) and on the coastlines of floodplains in middle and northern coastal China. There were about $5.7 \times 10^{4}$ ha of salt marshes in the late 1990s in China (Yang and Chen, 1995), but they have been heavily degraded due to multiple human impacts, such as reclamation, species invasions and pollution (He et al., 2014). An early estimate suggests that at least 708, 000 ha salt marshes were reclaimed and lost to coastal development between the 1950s and 1990s (Yang and Chen, 1995). On the other hand, the invasive cordgrass Spartina alterniflora has replaced 34,451 ha of native tidal marshes in China by 2007 since its first introduction in 1979 (Zuo et al., 2012). With increasing recognition of tidal marshes' values such as storm protection, pollution purification, and carbon storage, restoration of tidal marshes is gaining attention in China. To date, at least 125 tidal marsh restorations have been carried out across coastal China (Fig. 2b), with a total restored area of $\sim 38,000$ ha, accounting for $\sim 5 \%$ of the estimated total tidal marsh area in China in the 1950s (Fig. 3). 
Table 1. Number of projects for different restoration measures for different coastal ecosystems.

\begin{tabular}{|c|c|c|c|c|c|c|c|c|}
\hline \multirow{2}{*}{\multicolumn{2}{|c|}{ Restoration technique }} & \multicolumn{7}{|c|}{ Habitat type } \\
\hline & & Tidal Marsh & Mangrove & Seagrass & Coral reef & Sandy beach & Coastal waters & Others \\
\hline \multirow{6}{*}{ Biotic } & Vegetation planting & 59 & 364 & 10 & & & 46 & \\
\hline & Invasives removal & 14 & 28 & & & & & \\
\hline & Stock enhancement & & & & & & 161 & 3 \\
\hline & Coral larvae supplement & & & & 4 & & & \\
\hline & Coral transplant & & & & 9 & & & \\
\hline & Pest control & 1 & & & & & & \\
\hline \multirow{9}{*}{ Abiotic } & Reef construction & & & & 5 & & 215 & \\
\hline & Freshwater introduction & 23 & & & & & & \\
\hline & Berm/dike removal & 4 & & & & & 15 & \\
\hline & Tidal channel excavation & 7 & & & & & & \\
\hline & Beach nourishment & & & & & 88 & & \\
\hline & Fish farm removal & 10 & 7 & 1 & & 6 & 31 & \\
\hline & Debris removal & 5 & 9 & & & 12 & 16 & \\
\hline & Dredging & 10 & 4 & & & & 30 & \\
\hline & Topography reconstruction & 2 & & & & & & \\
\hline \multirow{2}{*}{ Combined } & Bird habitat enhancement & 13 & & & & & & \\
\hline & Marine ranching & & & & & & 46 & \\
\hline \multicolumn{2}{|c|}{ Un-reported } & & & & & & & 15 \\
\hline
\end{tabular}

Restoration technique categories generally followed Restoration Atlas in NOAA habitat conservation

(http://www.habitat.noaa.gov/restoration/restorationatlas/index.html). 
A number of abiotic and biotic measures have been adopted for tidal marsh restoration (Table 1). Biotic tidal marsh restorations include planting vegetation and removing invasive species (Table 1). Vegetation planting is often designed to reintroduce native, habitat-forming plant species into degraded marshes. Common plant species used include Suaeda salsa, Phragmites australis, Tamarix chinensis, Scirpus mariqueter, and Cyperus malaccensis $(\mathrm{Hu}$ et al., 2015; Jia et al., 2015; Li, 2010; Ning et al., 2014). In contrast, removing invasive species is often aimed to eradicate the invasive plant Spartina alterniflora, using multiple techniques, such as clipping, burning, herbicide application, and biological replacement by native species, such as Phragmites australis (Wang et al., 2008).

Abiotic restorations include freshwater introduction, fish farm removal, berm/dike removal, tidal channel excavation, debris removal, dredging, and topography reconstruction (Table 1). Marsh restoration projects by impounding salt marshes with berms/dikes and flooding them with freshwater have been implemented across coastal China (23 in our dataset; e.g., the Yellow River Delta, Cui et al., 2009; the Liao River Delta, Ministry of Environmental Protection, 2014), often aiming to reduce marsh soil salinity and create habitats for freshwater vegetation, birds, and sometimes fisheries. While this type of "restoration" is widely adopted and thought to be a valuable restoration approach in China, the newly created freshwater marshes replace salt marsh habitats that have their unique ecological functions. There has been recent recognition of potential limitation of this type of "restoration" (Howes et al., 2010; Li et al., 2015). In contrast, some salt marsh restorations in China (21 in our dataset) reconnect impounded salt marshes to tidal flow and the sea by removing dikes/berms, fish farms or excavating tidal channels, which have been widely adopted in marsh restorations in the U.S. and Europe (Wolters et al., 2005; Zedler et al., 2000). Among those tidal restorations in China, one in the Liao estuary removed 350 meters of a tide-blocking 
dam, and excavated tidal creeks of 2000 meters long in 2012, to reconnect marshes to tides to enhance the ecological functions of salt marshes (Department of Ocean and Fisheries of Liaoning Province, 2013). The value and efficacy of this type of tidal restoration vs. those of freshwater introductions still need to be evaluated in a comprehensive manner, prior to further recommendation for application at other sites or at larger scales. Additionally, there are also some substrate modification projects, by reconstructing topography in marshes (Wang, 2013), but such restoration projects remain only a few.

We also found 13 marsh restoration projects that employed both abiotic and biotic approaches. One most notable, carried out in the Yangtze River Estuary (Ruan, 2012; Wang, 2013), was to recreate waterfowl habitats with multiple biotic and abiotic restoration techniques, including adjusting plant communities, constructing hydrological networks, and adding birdseed.

\subsection{Mangrove restoration}

Historically, mangrove forests in China covered > 50, 000 ha (Lin, 1997), and were highly rich in species diversity (about 24 true mangrove species, accounting for one third of the world's total) (Li and Lee, 1997). Recent estimates, however, suggest that less than 23, 000 ha remained (Wang and Wang, 2007). Most China's mangroves are distributed in regions with dense population and rapid economic growth (e.g., Guangzhou, Shenzhen). With their important ecological and economic values increasingly recognized, China has made great efforts in mangrove restoration. Mangrove restoration is among the most intensively conducted coastal restorations in China (Fig. 3).

Mangrove restoration in China can be traced back to at least the 1950s and 1960s, when some Chinese overseas in Southeast Asia planted mangrove seedlings in bare tidal flats for 
reforestation in Fujian and Zhejiang provinces (Fig. 1; Wang and Wang, 2007). Mangrove restorations were stalled in the 1970s. In the late 1980s and early 1990s, the Chinese government established a national program aiming to enhance the storm/hurricane protection function of coastal forests, of which mangrove restoration was a key component (State Forestry Administration, 2011a). During the first phase of this project (1989 2000), the number of mangrove restoration projects rapidly increased (Fig. 1), and mangrove forests increased by $\sim 60$ ha per year (State Forestry Administration, 2011b). The second phase of this project (2001 to 2010) planned to plant 60,000 ha of mangroves in ten years. Currently, mangrove restorations have been carried out across its entire range (Fig. 2c). Indeed, recent analysis suggests that China's total mangrove area has been increasing, likely due to intense restorations over the last couple of decades (He et al., 2014; Liao and Zhang, 2014).

The main technique used for mangrove restoration in China is planting propagules and seedlings. This technique has now been viewed as a relatively mature one, with published governmental and scholarly guidelines (State Forestry Administration, 2011c; Zhejiang Bureau of Quality Technical Supervision, 2014). However, some mangrove restoration studies reported low success. An estimate suggests that the survival rate of mangrove plantings was only $57 \%$ in China (Chen et al., 2009). One important issue is that many mangrove plantings suffered from high mortalities, particularly in relatively cold, wave-exposed, or high salinity sites (Chen et al., 2009). Furthermore, a number of mangrove restorations used a single species or exotic species, resulting in reduced mangrove species diversity and issues related to species invasion (Ren et al., 2009).

Biological invasion, as mentioned above, is a severe threat to mangroves in China. Currently, Spartina alterniflora is invading the entire Chinese coast, and has significantly negative 
impacts on mangrove ecosystems (Wan et al., 2009). Removal techniques, as in tidal marsh restorations, have been used to eradicate Spartina in mangroves. Additionally, biological replacement using mangrove species, including Sonneratia apetala, Kandelia obovata, and Aegiceras corniculatum, has been applied (Feng et al., 2014; Zhou et al., 2015). Of those mangrove species used to replace Spartina, Sonneratia apetala was exotic in China, too, and was introduced to Dongzhaigang Mangrove Nature Reserve in Hainan Island from Bengal in 1985. Whether this exotic mangrove will cause new ecological invasions similar to Spartina has attracted attention and needs to be further studied (Ren et al., 2009; Zhou et al., 2015).

\subsection{Seagrass restoration}

A total of 22 seagrass species belonging to 10 genera are distributed in China, accounting for about $30 \%$ of seagrass species worldwide, with a total existing area of 8765.1 ha (Zheng et al., 2013). Multiple studies suggest that China's seagrasses have been severely degraded, and in many places have or will become extinct, due to human disturbances including reclamation, fishing, and aquaculture (Huang et al., 2006; Yang and Yang, 2009; Zheng et al., 2013). While seagrass ecosystems globally are valued for carbon/nitrogen cycling, wave mitigation, sediment stabilization, and providing feeding grounds for megaherbivores (e.g., sea turtles and dugongs; Orth et al., 2006) (Waycott et al., 2009), their values have not been widely recognized in China. Some early Chinese researchers, however, transplanted eelgrass into coastal aquaculture ponds in 1989 to purify water, thereby increasing the yield of aquaculture (Ren et al., 1991). This earliest record of seagrass transplantation also shed light on China's seagrass restoration.

In general, however, China's seagrass restoration has not been carried out until the recent few years, and the total number of conducted projects remains only a few (Fig. 1), with a total 
restored area of $<30$ hectares, which accounts for $<0.1 \%$ of China's total seagrass area (Fig. 3). The primary method used in these restorations is transplantation. The first seagrass restoration project was launched in 2007 in Weihai City, Shandong Province, which transplanted $\sim 100,000$ plugs of Zostera marina to restore 3.4 ha of Zostera seagrass beds (Gu, 2011). Since then, ten other seagrass transplant restoration projects were carried out in Shandong, Guangdong, Guangxi, and Hainan provinces (Fig. 2d). Seagrass species used in these restorations mainly included Zostera marina, Halophila ovalis, Zostera japonica, Halodule uninervis, Halophila beccarii, and Ruppia maritima (Qiu et al., 2014). However, most of these projects suffered from low seagrass survival rates and high cost (Qiu et al., 2014), and had a very small project area (with only five having a restoration area of $>1$ ha), which may limit the positive effects of self-sustaining feedback critical in seagrass restorations (Katwijk et al., 2015). While some experiments tested if Zostera marina in the Yellow Sea could establish populations from seeds, such a seeding method has not yet been applied in restoration practices (Pan et al., 2014). In addition, in 2011, Hepu Dugong State Nature Reserve, Guangxi Province restored 12 ha seagrass habitats by removing fish farms to enhance habitat quality and achieve gradual seagrass recovery (Environmental Protection Bureau of Guangxi, 2011). This type of seagrass restoration by protecting or improving habitats for seagrass natural recruitment has not been adopted in other places in China.

\subsection{Coral reef restoration}

China's coral reefs are found mainly in Guangdong, Guangxi, Fujian, and Hainan, Hong Kong, and around the oceanic islands in South China Sea. There are in total 174 species of reef-building corals in China, accounting for one-third of the world's total (Zou, 2001). China's coral reefs have been highly degraded with human threats including coastal development, pollution, overfishing, coral mining, and climate change, resulting in an overall 
cover decline of $80 \%$ (Qiu, 2012; He et al., 2014). Many species are now locally extinct or threatened. There is urgent need for manual intervention of this unprecedented degradation trend. However, while coral reefs have values such as sustaining fisheries production that many local economies in coastal China depend on, such values still need to be recognized by the government, local fishing communities, and the general public to promote restoration.

The earliest records of coral reef experimental restoration trials were in 1993 and 1994, when scientists transplanted reef-building corals into reefs near Sanya, Hainan (Chen et al., 1995; Yu et al., 1996). In general, however, coral reef restoration practices have not started in China until the early 2000s (Fig. 1), and the number of conducted projects with available reports is only 12 . To date, the total restored coral reef area is $\sim 130$ hectares, accounting for only $0.02 \%$ of China's total coral reef area in 2002 (Fig. 3). The methods employed in these restorations are mainly coral reef transplantation, coral larvae supplement and artificial reef construction (Table 1). Transplantation is the most widely applied method for coral reef restoration. For instance, a restoration project in 2003 transplanted 3500 coral colonies into the Daya Bay, Guangdong Province (Anonymous, 2003). Coral larvae supplement includes larval rearing, releasing, and reattachment (Li et al., 2014). Construction of artificial reefs, made of steel, cement, and others, was often implemented with coral transplantation (ER-China, 2012). It should be noted that, interestingly, in a coral reef restoration trial in 2012 , the native herbivorous fish Siganus guttatus that feeds on algae were added to reduce the abundance of competitive algae on corals. This trial has been reported to successfully increase coral cover by $5 \%$ (Lin et al., 2014). However, this method has not yet been applied in China's coral reef restoration practices.

\subsection{Sandy beach restoration}


About one-third of China's 18, $000 \mathrm{~km}$ mainland coastlines are sandy beaches, and $70 \%$ of the sandy beaches suffer from coastal erosion (Xia et al., 1993). While sandy beach restorations in China include fish farm removal, debris removal, etc., most current restorations are mainly by beach nourishment (Table 1), the main objectives of which include storm protection, creation of recreational opportunities, and enhancement of other ecological and economic values of beaches (Zhuang et al., 2011). However, there are currently no published assessments of how beach nourishment affects sandy beach biodiversity (e.g., turtles, benthic fauna) and ecological processes (but see Schlacher et al., 2012 for an assessment from other countries). Mainland China carried out its first beach nourishment project in Xinghai Bay, Dalian city in 1994 (Cai et al., 2010), though beach nourishment was not widely carried out in mainland China until recent years (Fig. 1). To date, beach nourishment restorations have increased rapidly, and are distributed across the entire Chinese coast (Fig. 2f). As one of the demonstrations for northern China, a beach nourishment project restored a total of 3.42 ha of sandy beaches in Beidaihe area on the coast of Hebei province between 2012 and 2013 (Luo et al., 2015). Most sandy beach nourishment projects in China are often characterized by small size.

\subsection{Coastal waters restoration}

Another seriously degraded type of coastal ecosystems in China are coastal waters. China's coastal waters have been deteriorating due to pollution, eutrophication and overfishing among other human impacts (He et al., 2014). About 56\% of fisheries in China's exclusive economic zones have collapsed or been overexploited by 2010, a number still increasing (Sea Around Us, http://www.seaaroundus.org/). Fish diversity has declined (He et al., 2014), and many endangered species, including marine mammals (e.g., the Indo-Pacific humpback dolphin, Sousa chinensis), have been threatened (Jefferson and Hung, 2004). 
As fisheries resources are vital to many coastal economies in China, restoration of coastal waters for enhancing fisheries has been carried out in China since the late 1970s (Fig. 1). While fishing exclosure and pollution reduction that were generally national- or provincial-level regulations or policies (these measures have been reviewed elsewhere; Shen and Heino, 2014), around 10 restoration projects were carried out per year between 1978 and 1986 to intentionally restore fisheries. Such restorations, however, were generally discontinued between the late 1980s and the late 1990s, likely due to a lack of funding (Yang, 2007). Since the 2000s, restoration of coastal waters has been resumed, and the number of restoration projects conducted per year has increased from $<20$ to 40 (Fig. 1). In 2010, China issued a new national plan for stock enhancement for 2011-2015, which set new goals of fishery enhancement in its coastal waters (Ministry of Agriculture, 2010).

Three main approaches are used for restoration of coastal waters in China. The first is stock enhancement, releasing larvae and juveniles of fish and invertebrates into coastal waters to augment their natural supply. An earliest released reared Penaeus chinensis juveniles in the Yellow and Bohai Seas in the 1980s (Wang et al., 2006). Other species that were targets of restoration included fish (e.g., Pseudosciaena crocea, Pagrosomus major, and Sparus macrocephalus), shrimps (e.g., Penaeus merguiensis, Penaeus penicillatus, and Penaeus monodon), clams (e.g., Chlamys farreri, Pecten yessoensis, and Meretrix meretrix), and crabs (e.g., Portunus trituberculatus, and Eriocheir sinensis). The total number of species used was > 45 in the 2010s (Ministry of Agriculture, 2010). The total amount of fish, shrimps, clams, and crabs used for stock enhancement was about 53.9 billion between 2001 and 2010 (Shen and Heino, 2014). The second main approach to restoring coastal waters is construction of artificial reefs to enhance habitats, the first project of which was implemented in Beibu Gulf, 
Guangxi, in 1979 (Yang, 2007). A recent estimate suggests that about 31.52 million cubic meters of artificial reefs were deployed in 463.72 square kilometers of coastal waters around China between 1985 and 2010 (Yang et al., 2011). Multiple types of materials are used to construct artificial reefs, including stone blocks, reinforced concrete/cement structures, and scrap materials such as steel or wooden boats, and reinforced concrete structures are most commonly used, accounting for $67.82 \%$ of all constructed reefs (Yang et al., 2011). Furthermore, marine ranching, an approach combining juvenile fish releasing, artificial reef construction, and algal transplantation, is also adopted in restoration of fisheries resources in China (Bartley et al., 1999; Zhang et al., 2003). To date, more than 40 embryonic forms of marine ranches have been established from northern to southern coastal China. Besides these three main restoration approaches, a number of other methods, such as dike and fish farm removal, debris removal, dredging, and algal plantation (Table 1), have been adopted in coastal waters restorations in China, often with a goal to improve water quality.

\section{EXISTING ISSUES}

Clearly, China's coastal restoration has entered a rapidly developing stage and is now a national-level conservation effort. Such rapidly increasingly restoration efforts have great values and are crucial to enhancing China's coastal environments. However, the successes of current coastal restorations remain mixed. For example, tidal marsh area (Niu et al., 2012), coral cover (He et al., 2014), and fisheries (see Sea Around Us, http://www.seaaroundus.org/) have all been shown still to be rapidly declining across China since the 2000 s, a period when significant restoration efforts have been implemented. Also, while many salt marsh projects have been carried out to remove invasive Spartina alterniflora, which might be effective at site scales, the total marsh area occupied by this highly clonal and reproductive species has continued to increase in China (Zuo et al., 2012; Ministry of Agriculture, 2015). Further, 
although mangrove area in China has shown sign of increasing in the 2000s, the efficacy of many mangrove restorations was low (see above). While detailed assessments of such restorations using long-term monitoring data (often unavailable currently) still need to be performed, our synthesis reveals that at least the following issues exist in current coastal restorations.

\subsection{Lack of systematic planning}

Our study has shown that while mangrove and coastal waters restorations have been planned at national levels, restorations of many other coastal ecosystems have generally not been planned at large temporal or spatial scales. China's success in reversing the declining trend in mangroves through restoration with national plans has shown the value of such systematic plans. However, China's current restoration planning has emphasized a few types of coastal ecosystems over others, and there are important mismatches between current restoration efforts and degradation degree, ecosystem value, and natural distribution of coastal ecosystems. For instance, although seagrass and coral reef ecosystems are most severely degraded, their restorations have been much fewer than mangroves and tidal marshes (Fig. 3). Similarly, while coral reef ecosystems have the highest values of ecosystem services (with a global average of 352,249\$/ha per year in USD 2007; Costanza et al., 2014), restoration efforts on this type of coastal ecosystem in China have been the lowest (Fig. 3). Indeed, as above, creations of freshwater marshes upon salt marsh habitats in China are likely due to under-appreciation of the values of salt marshes (often viewed as wastelands in China, as in the past in the U.S. and Europe). The ecosystem service value system for coastal ecosystems is rapidly changing in China with socio-economic development. Adjusting current value systems and promoting recognition of the ecosystem services values of coastal ecosystems, including the fisheries-sustaining function of tidal marshes, seagrasses, and coral reefs, will 
be critical to furthering restoration efforts. Furthermore, for some type of coastal ecosystems, there are also mismatches between current restoration and natural distribution. Most obviously, despite widespread seagrass degradation across China, seagrass restorations have concentrated in Shandong and Guangxi provinces (Fig. 2d).

\subsection{Outdated restoration techniques}

Another major issue is that China's current restorations have not adopted updated ecological principles underlying the community assembly and functioning of coastal ecosystems. Our study has shown that China's coastal restorations often use simple introduction of species or removal of invasive species, or modify the abiotic environment by freshwater introduction, beach nourishment, fish farm removal, dredging or hydrological modification (Table 1). Much fewer projects employed both abiotic and biotic approaches, but these were often simple combinations (Table 1). Few restorations (except some projects that applied biological replacement to restore Spartina-invaded salt marshes and mangroves, see above) have considered the interactive processes of ecological communities, such as how hydrology affects the cascading effects of predators, or how salinity affects the positive and negative interactions between multiple plant species. This, however, is in direct contrast to many fundamental theories on community assembly and ecosystem functioning in coastal ecosystems. For instance, species interactions in communities globally have been shown to shift from competition to facilitation with increasing environmental stress (He et al., 2013), such as anoxia, salinity and disturbance stresses common in degraded coastal ecosystems. Current planting designs in China's coastal restorations, as well as in many other countries, however, often emphasize minimizing competition among out-planted propagules to maximize planting success (Halpern et al., 2007). Thus, current coastal restoration techniques that often only address environmental factors and single species performances have lagged 
behind key advances in ecological science where interactions among species and the impacts of environmental factors on species interactions have been well revealed.

Another notable technique issue in China's coastal restoration is use of non-native species. A well-known lesson of this is the early use of invasive Spartina alterniflora for shoreline stabilization and tidal marsh restoration, which, ironically, has now been targeted for removal and marsh restoration, due to their widely documented negative effects on native marsh communities across the Chinese coast (Zuo et al., 2012). Similarly, as described above, many of China's mangrove restorations have used non-native species including Sonneratia apetala. The ecological consequences of this exotic mangrove species are less well studied relative to Spartina alterniflora, but there was a recent effort for removal from a nature reserve in Guangxi in 2013 (Guangxi Oceanic Administration, 2014). There are also reports of use of non-native species in restorations of other types of coastal ecosystems in China (Zhou et al., 2015). Continued use of exotic species in China's coastal restorations, if left uncontrolled, may pose new threats to coastal ecosystems.

\subsection{Deficiency of restoration research, long-term assessment, and adaptive management}

Our study also shows that most restoration practices in China were implemented without prior restoration experiments and/or posterior long-term monitoring and assessment (also see Chen et al., 2012). Of the 1011 projects included in our analysis, only 122 (i.e., 12\%) were reported in scientific papers and books (other projects were mainly from project news or reports). This indicates a clear lack of scientific research and assessment on restoration projects in China. Also, we found that the majority of China's coastal restorations lasted for less than a couple of years (many China's state-funded projects related to restorations, such as the National High Technology Research and Development Program of China, allow only 
three years in total), and there were few follow-up assessments and management of restorations (Cao and Wong, 2007). In contrast, however, it often takes many years even decades for a degraded ecosystem, such as the San Francisco Bay marsh restoration project in the U.S. (Williams and Faber, 2004), to recover.

\subsection{Participation absence of local communities and private parties besides government}

Our analysis finds that of the 1011 coastal restoration projects analyzed, 993 projects (98\%) were sponsored solely by government, while those by private parties $(n=14)$, non-governmental organizations $(n=2)$, and others $(n=2)$ (NGO and government collaborations) accounted for $<2 \%$ in total (Fig. 4). This is not surprising, given that China has a tradition as a primarily top-down, government-dominated country. While this government-dominated model of coastal restorations in China has advantages, such as strong enforcement, coastal restoration is often a long-term strategic task, and participation of private sectors, NGOs, and local communities can be an important factor affecting its success (Stone et al., 2008; Le et al., 2014). Mangrove reforestations by fishermen and farmers in China in the 1960s (see above), in the Philippines (Walters, 1997), and in India (Stone et al., 2008) indicate the potential value of community-based coastal restorations. While increasing governmental investment will still be fundamental to China's coastal restorations, a lack of participation and cooperation of local communities, as well as of non-governmental organizations and companies, may slow down the progress, and even hinder the success of coastal restorations.

\section{SHIFTING PARADIGMS IN CHINA'S COASTAL RESTORATION}

Accordingly, current paradigms in China's coastal restoration must be transformed for improvements. We suggest at least the following transformations will be essential (Fig. 5). 


\subsection{Planning restorations with multiple goals across temporal and spatial scales}

China's coastal restoration should be planned in a more systematic way, and establish plans for other types of coastal ecosystems besides mangroves and coastal waters. Such plans should consider the degradation degree and natural distribution of different types of coastal ecosystems, better recognize their ecosystem services values, identify priority restoration regions/areas across local, regional or national scales (Williams and Faber, 2001), and be coordinated temporally. Such spatial and temporal coordination can substantially enhance restoration efficiency (Neeson et al., 2015). Ideally, restoration plans should balance multiple competing goals including science, biodiversity and ecological values, and human needs, particularly those of local communities, and address potential interactions with other local or regional conservation strategies, such as establishment of marine protected areas and regional fishing or pollution regulations, to promote synergistic interactions.

\subsection{Advancing restoration techniques by incorporating key ecosystem processes}

Future restorations should employ techniques that improve an ecosystem's state not only by biotically or abiotically engineering its external components, such as vegetation coverage, salinity, and hydrology, but also by enhancing self-sustaining processes internal to the ecosystem, such as competition, facilitation, and food web interactions. In cases where manipulating ecosystem internal processes is costly or unfeasible, restorations should consider the effects of changes in an ecosystem's physical environment on its internal processes, and modify an ecosystem's physical environment to a point where ecosystem self-sustaining internal processes are optimized while the costs of physical environment engineering remain low and acceptable. An increasingly recognized example is the application of facilitation theory in coastal restorations. As described above, most planting 
designs in current coastal restorations emphasize minimizing competition among out-planted propagules to enhance success. Recent coastal restoration experiments, however, have shown that planting organisms adjacent to each other rather than at a distance from one another can harness facilitative interactions and enhance the success of out-planted organisms (Halpern et al., 2007; Silliman et al., 2015). Thus, adjusting planting designs to incorporate facilitative interactions may likely amplify restoration efforts (Silliman et al., 2015), such as the survival rates of mangrove plantings that have been of concern in China. This new restoration technique is arguably important, as it can enhance success with no added cost.

Improved coastal restorations should also consider the interactions between ecosystems. Coastal ecosystems are often not isolated. Rather, they interact with one another in multiple ways (Ramos-Scharrón et al., 2015). For example, coral reef ecosystems adjacent to mangroves have higher fisheries production than those without nearby mangroves (Mumby et al., 2004). Many coastal marine species have long-distance movements (Luschi et al., 2003) or larval dispersal (Allison et al., 1998; Baskett et al., 2007). While this type of restoration remains immature, across-habitat or -ecosystem restorations can be promising and deserve attention in future research and restoration practices.

\subsection{Prioritizing restoration research and assessment}

Future restorations should also be implemented with well-performed prior restoration research. Such restoration research may include site selection, diagnosis of the factors causing degradation, screening of target species and restoration technique, and restoration experiments (Elliott et al., 2007). Large-scale restoration projects may be implemented only when restoration experiments at smaller scales have proven to be effective. Further, monitoring of key response and environmental variables should be implemented immediately 
with the restoration project. And such restoration monitoring should be continued post the main restoration implementation phase. Monitoring data should be analyzed regularly, and adjustments should be performed to ensure that the ecosystem under restoration is developing in a desirable way (Thom, 2000), and that the restored ecosystem is resistant to episodes of human disturbances, such as climate extremes. Employing adaptive management is key to the long-term success of restorations, also because it provides a way to incorporate the updated science into management decisions and to use management outcomes as opportunities to improve scientific understanding and provide feedback to the decision system, therefore avoiding shortsighted restoration practices (Tong et al., 2014).

\subsection{Encouraging participation of local communities and other parties}

Finally, we suggest that to enhance coastal restoration in China, new policies should be established to improve participation of local communities, NGOs, private companies/foundations, and other interest bodies in coastal restoration. A consensus for coastal restoration among those interest parties and the government, which can be achieved through publicity and education, may promote China's coastal restoration as a multi-win conservation strategy.

\section{CONCLUDING REMARKS}

This synthesis provides a unique perspective on China's coastal restoration, and have broad implications for coastal environmental management policies and practices. Our work shows that China's coastal restoration has recently entered a rapidly developing stage, with an increasing number of restoration projects carried out per year in a variety of coastal ecosystems including tidal marshes, mangroves, seagrasses, coral reefs, sandy beaches, coastal waters, and others. Our work also reveals that the current planning, techniques, 
research/assessment, and participation models of China's coastal restoration remain largely inadequate for restoration to be an efficient strategy to halt coastal degradation trends in China.

To promote the success of China's coastal restoration, we suggest that the outdated paradigms underlying current restorations be transformed. Especially, future restorations should be better planned with multiple goals, address interactions with other conservation strategies, and be coordinated across temporal and spatial scales; restoration techniques should be advanced by combining ecosystem internal processes with physical engineering of external ecosystem components and by addressing cross-ecosystem interactions; restoration practices should be implemented with well-performed prior restoration research, long-term monitoring, and adaptive management; and finally, new policies should be established to encourage participation of local communities, NGOs, private companies/foundations, and other interest bodies in coastal restoration, to promote China's coastal restoration as a multi-win conservation strategy. We suggest that efforts should be taken to promote recognition of the ecosystem services values of coastal ecosystems and to adjust the value system for coastal ecosystems to better reflect China's socio-economic development and current position in the world. China is not the only rapidly developing country that suffers from intense coastal degradation. The lessons from China's coastal restoration practices and the framework for improvements we present here should also inform many other rapidly developing coastal countries worldwide.

\section{ACKNOWLEDGEMENTS}

This study was funded by National Key Basic Research Program of China (2013CB430406), China National Funds for Distinguished Young Scientists (51125035), and National Science 
Foundation for Innovative Research Group (51121003).

\section{REFERENCES}

Allison, G.W., Lubchenco, J., Carr, M.H., 1998. Marine reserves are necessary but not sufficient for marine conservation. Ecol. Appl. 8 (1), S79-S92.

Anonymous, 2003. China's first coral reef transplantion project. South China Fisheries Science 7, 4-4.

Barbier, E.B., Hacker, S.D., Kennedy, C., Koch, E.W., Stier, A.C., Silliman, B.R., 2011. The value of estuarine and coastal ecosystem services. Ecol. Monogr. 81 (2), 169-193.

Barbier, E.B., Koch, E.W., Silliman, B.R., Hacker, S.D., Wolanski, E., Primavera, J., et al., 2008. Coastal ecosystem-based management with nonlinear ecological functions and values. Science 319 (5861), 321-323.

Bartley, D. M., Howell, B. R., Moskness, E., \& Svasand, T, 1999. Marine ranching: A global perspective. In Stock enhancement and sea ranching. Papers from the First International Symposium on Stock Enhancement and Sea Ranching, Bergen, Norway, 8-11 September 1997, pp. 79-90.

Baskett, M.L., Micheli, F., Levin, S.A., 2007. Designing marine reserves for interacting species: Insights from theory. Biol. Conserv. 137 (2), 163-179.

Bayraktarov, E., Saunders, M.I., Abdullah, S., Mills, M., Beher, J., Possingham, H.P., et al., 2015. The cost and feasibility of marine coastal restoration. Ecol. Appl. DOI: 10.1890/15-1077.1.

Benayas, J.M.R., Newton, A.C., Diaz, A., Bullock, J.M., 2009. Enhancement of biodiversity and ecosystem services by ecological restoration: A meta-analysis. Science 325 (5944), 1121-1124.

Cai, F., Dean, R.G., Liu, J.H., 2010. Beach nourishment in China: Status and prospects. Proc. 
16th Int. Conf. Coastal Engineering, Shanghai, Paper No. 32.

Cao, W.Z., Wong, M.H., 2007. Current status of coastal zone issues and management in China: A review. Environ. Int. 33 (7), 985-992.

Chen, B., Yu, W.W., Liu, W.H., Liu, Z.H., 2012. An assessment on restoration of typical marine ecosystems in China - Achievements and lessons. Ocean Coast. Manage. 57, 53-61.

Chen, G., Xiong, S.L., Xie, J.N., Zou, X.P., Cui, Y.C., 1995. A study on the transplantation of reef-building corals in Sanya waters, Hainan Province. Tropic Oceanology 14 (3), $51-57$.

Chen, L.Z., Wang, W.Q., Zhang, Y.H., Lin, G.H., 2009. Recent progresses in mangrove conservation, restoration and research in China. J. Plant. Ecol. 2 (2), 45-54.

Costanza, R., de Groot, R., Sutton, P., van der Ploeg, S., Anderson, S.J., Kubiszewski, I., et al., 2014. Changes in the global value of ecosystem services. Global Environ. Change 26, 152-158.

Cui, B.S., Yang, Q.C., Yang, Z.f., Zhang, K.J., 2009. Evaluating the ecological performance of wetland restoration in the Yellow River Delta, China. Ecol. Eng. 35 (7), 1090-1103.

De Jonge, V.N., De Jong, D.J., 2002. Ecological restoration in coastal areas in the Netherlands: Concepts, dilemmas and some examples. Ecological Restoration of Aquatic and Semi-Aquatic Ecosystems in the Netherlands (NW Europe). Springer Netherlands, 7-28.

Department of Ocean And Fisheries Of Liaoning Province, 2013. Multiple measures simultaneously strengthening the construction of ocean ecological environment, Panjin City. http://www.lnhyw.gov.cn/hyhb/stbh/201311/t20131106_1209022.html. Elliott, M., Burdon, D., Hemingway, K.L., Apitz, S.E., 2007. Estuarine, coastal and marine 
ecosystem restoration: Confusing management and science-a revision of concepts. Estuar. Coast. Shelf Sci. 74 (3), 349-366.

Environmental Protection Bureau of Guangxi, 2011. Reconstruction seagrass habitatrestoration and protection of seagrass ecosystem. http://www.gxepb.gov.cn/zrst/qyst/201103/t20110323_2817.html.

ER-China, 2012. Amazing South China Sea. http://www.er-china.com/index.php? $\mathrm{m}=$ content $\& \mathrm{c}=$ index $\& \mathrm{a}=$ show $\&$ catid $=15 \& \mathrm{id}=5$ 0450.

Feng, J.X., Guo, J.M., Huang, Q., Jiang, J.X., Huang, G.M., Yang, Z.W., et al., 2014. Changes in the community structure and diet of benthic macrofauna in invasive Spartina alterniflora wetlands following restoration with native mangroves. Wetlands 34 (4), 673-683.

Foster, N.M., Hudson, M.D., Bray, S., Nicholls, R.J., 2013. Intertidal mudflat and saltmarsh conservation and sustainable use in the UK: A review. J. Environ. Manage. 126, 96-104.

Fu, X.M., Shao, C.L., Wang, C.Y., Han, L., Li, G.Q., Liu, G.X., et al., 2009. Investigation on the status of coral reef resources and medicinal research in China II . resource decline status, protection and management. Periodical of Ocean University of China 4,23

Guangxi Oceanic Administration, 2014. Marine environmental quality Gazette in 2013, Guangxi Zhuang Autonomous Region. http://www.gxoa.gov.cn/gxhyj_hyhb_jcgcyb/2014/06/17/11aa1618f2d845d0b2d8e3f e25090bc5.html.

Halpern, B.S., Silliman, B.R., Olden, J.D., Bruno, J.P., Bertness, M.D., 2007. Incorporating positive interactions in aquatic restoration and conservation. Front. Ecol. Environ. 5 


$$
\text { (3), 153-160. }
$$

He, Q., Bertness, M.D., Altieri, A.H., 2013. Global shifts towards positive species interactions with increasing environmental stress. Ecol. Lett. 16 (5), 695-706.

He, Q., Bertness, M.D., Bruno, J.F., Li, B., Chen, G.Q., Coverdale, T.C., et al., 2014. Economic development and coastal ecosystem change in China. Sci. Rep. 4: 5995. Howes, N.C., FitzGerald, D.M., Hughes, Z.J., Georgiou, I.Y., Kulp, M.A., Miner, M.D., et al., 2010. Hurricane-induced failure of low salinity wetlands. P. Natl. Acad. Sci. USA 107 (32), 14014-14019.

Hu, Z.J., Ge, Z.M., Ma, Q., Zhang, Z.T., Tang, C.D., Cao, H.B., et al., 2015. Revegetation of a native species in a newly formed tidal marsh under varying hydrological conditions and planting densities in the Yangtze Estuary. Ecol. Eng. 83, 354-363.

Huang, X.P., Huang, L.M., Li, Y.H., Xu, Z.Z., Fong, C.W., Huang, D.J., et al., 2006. Main seagrass beds and threats to their habitats in the coastal sea of South China. Chin. Sci. Bull. 51 (2), 136-142.

Jefferson, T.A., Hung, S.K., 2004. A review of the status of the Indo-Pacific humpback dolphin (Sousa chinensis) in Chinese waters. Aquat. Mamm. 30 (1), 149-158.

Jia, M.M., Wang, Z.M., Liu, D.W., Ren, C.Y., Tang, X.G., Dong, Z.Y., 2015. Monitoring loss and recovery of salt marshes in the Liao Rever Delta, China. J. Coastal. Res. 31(2), 371-377.

Katwijk, M.M., Thorhaug, A., Marbà, N., Orth, R.J., Duarte, C.M., Kendrick, G.A., et al., 2015. Global analysis of seagrass restoration: the importance of large - scale planting. J. Appl. Ecol. DOI: 10.1111/1365-2664.12562.

Laegdsgaard, P., 2006. Ecology, disturbance and restoration of coastal saltmarsh in Australia: A review. Wetlands Ecol. Manage. 14 (5), 379-399.

Le, H.D., Smith, C., Herbohn, J., 2014. What drives the success of reforestation projects in 
tropical developing countries? The case of the Philippines. Glob. Environm. Change $24,334-348$.

Li, L., 2010. Tamarix forestry vegetation of wetland restoration projects in Changyi passed expert review. Shandong Fisheries 27 (11), 59-59.

Li, M.S., Lee, S.Y., 1997. Mangroves of China: A brief review. For. Ecol. Manage. 96 (3), 241-259.

Li, S.Z., Cui, B.S., Xie, T., Zhang, K.J., 2015. Diversity pattern of macrobenthos associated with different stages of wetland restoration in the Yellow River Delta. Wetlands DOI $10.1007 / \mathrm{s} 13157-015-0641-7$.

Li, Y.C., Lan, J.X., Zheng, X.Q., Wang, D.R., 2014. Preliminary assessment of the coral reef restoration in areas of Zhaoshu Island, Xiasha Islands. Journal of Applied Oceanography 33 (3), 348-353.

Liao, B.W., Zhang, Q.M., 2014. Area, Distribution and species composition of mangroves in China. Wetland Sci. 12 (4), 435-440

Lin, L.S., Chen, Y.J., Zhang, J., 2014. A coral reef ecosystem restoration method utilizes rabbitfish Siganus guttatus. http://epub.sipo.gov.cn/patentoutline.action.

Lin, P., 1997. Mangrove ecosystem in China. Science Press, Beijing.

Lotze, H.K., Lenihan, H.S., Bourque, B.J., Bradbury, R.H., Cooke, R.G., Kay, M.C., et al., 2006. Depletion, degradation, and recovery potential of estuaries and coastal seas. Science 312 (5781), 1806-1809.

Luo, S.L., Cai, F., Liu, H.J., Lei, G., Qi, H.S., Su, X.Z., 2015. Adaptive measures adopted for risk reduction of coastal erosion in the People's Republic of China. Ocean Coast. Manage. 103, 134-145.

Luschi, P., Hays, G.C., Papi, F., 2003. A review of long - distance movements by marine turtles, and the possible role of ocean currents. Oikos 103 (2), 293-302. 
McKinnon, M.C., Cheng, S.H., Garside, R., Masuda, Y.J., Miller, D.C., 2015. Sustainability: Map the evidence. Nature 528 (7581), 185-187.

Ministry of Agriculture, 2010. Overll Planning of National Stock Enhancement of Aquatic Organism in the period of 2011-2015. http://www.moa.gov.cn/govpublic/YYJ/201012/t20101219_1793509.htm.

Ministry of Agriculture, 2015. Hangu forestry workstations of Tianjin Binhai New Area carried out Spartina alterniflora governance tests. http://www.agri.cn/V20/ZX/qgxxlb_1/tj/201509/t20150908_4821075.htm.

Ministry of Environmental Protection, 2014. Major Science and Technology Program for Water Pollution Control and Treatment. http://nwpcp.mep.gov.cn/cgzl/cgbg/201405/t20140506_271585.html.

Morsing, J., Frandsen, S. I., Vejre, H., Raulund-Rasmussen, K., 2013. Do the principles of ecological restoration cover EU LIFE Nature cofunded projects in Denmark? Ecol. Soc. 18(4): 15 .

Mumby, P.J., Edwards, A.J., Arias-González, J.E., Lindeman, K.C., Blackwell, P.G., Gall, A., et al., 2004. Mangroves enhance the biomass of coral reef fish communities in the Caribbean. Nature 427 (6974), 533-536.

Neeson, T.M., Ferris, M.C., Diebel, M.W., Doran, P.J., O Hanley, J.R., McIntyre, P.B., 2015. Enhancing ecosystem restoration efficiency through spatial and temporal coordination. P. Natl. Acad. Sci. USA 112 (19), 6236-6241.

Ning, Q.Y., Li, Y.H., Mo, Z.N., 2014. The evaluation on the effect of marine saltmarsh ecological restoration project in Zhushan, Guangxi. Journal of Quanzhou Normal University 6 (32), 25-29

Niu, Z.G., Zhang, H.Y., Wang, X.W., Yao, W.B., Zhou, D.M., Zhao, K.Y., et al., 2012. Mapping wetland changes in China between 1978 and 2008. Chin. Sci. Bull. 57 (22), 
2813-2823.

Orth, R.J., Carruthers, T.J., Dennison, W.C., Duarte, C.M., Fourqurean, J.W., Heck, K.L., et al., 2006. A global crisis for seagrass ecosystems. Bioscience 56 (12), 987-996.

Pan, J.H., Jiang, X., Li, X.J., Han, H.W., Zhang, Z.Z., Li, Z.L., et al., 2014. An effective method for collecting and storing seeds from Zostera marina (Eelgrass) in the Yellow Sea, China. Restor. Ecol. 22 (6), 716-722.

Qiu, G.L., Fan, H.Q., Li, L.X., 2014. Restorations of the intertidal seagrass beds. China Forestry Publishing House, Beijing.

Qiu, J., 2012. Chinese survey reveals widespread coastal pollution, massive declines in coral reefs, mangrove swamps and wetlands. Nature News. http://www.nature.com/news/chinese-survey-reveals-widespread-coastal-pollution-1. 11743.

Ramos-Scharrón C.E., Torres-Pulliza D., Hernández-Delgado E.A., 2015. Watershed-and island wide-scale land cover changes in Puerto Rico (1930s-2004) and their potential effects on coral reef ecosystems. Sci. Total Environ. 506, 241-251.

Ren, G.Z., Zhang, Q.X., Wang, J.C., Wang, D.J., 1991. Transplanting eelgrass in shrimp ponds to increase products of Penaeus chinensis O'sbeck. Mar. Sci 1, 52-57.

Ren, H., Lu, H., Shen, W., Huang, C., Guo, Q., Li, Z.A., et al., 2009. Sonneratia apetala Buch. Ham in the mangrove ecosystems of China: An invasive species or restoration species? Ecol. Eng. 35 (8), 1243-1248.

Ruan, G.X., 2012. Ecological benefits of the ecological control of Spartina alterniflora Loisel and the improvement of birds habitats in Chongming Dontan. Journal of Anhui Agri. Sci. 40 (23), 11799-11801.

Schlacher T.A., Noriega R., Jones A., Dye T., 2012. The effects of beach nourishment on benthic invertebrates in eastern Australia: Impacts and variable recovery. Sci. Total 
Environ. 435, 411-417.

Gu, J., 2011. Study on the restoring technology of Zostera resources.

http://www.kjhm.org.cn/app/Cresult.aspx?id=452.

Shen, G.M., Heino, M., 2014. An overview of marine fisheries management in China. Mar. Policy 44, 265-272.

Silliman, B.R., Schrack, E., He, Q., Cope, R., Santoni, A., van der Heide, T., et al., 2015. Facilitation shifts paradigms and can amplify coastal restoration efforts. P. Natl. Acad. Sci. USA 112 (46), 14295-14300.

State Forestry Administration, 2011a. Constructing shoreline rock - solid " green wall ". http://www.forestry.gov.cn/portal/main/s/195/content-512749.html.

State Forestry Administration, 2011b. Total area of 82,000 hectares of mangrove resources in China. http://www.forestpest.org/senfang/news/lyxw/2011-06-28/article_3738.shtml.

State Forestry Administration, 2011c. Technical regulations for mangrove plantation. Standards Press of China, Beijing.

State Forestry Administrationm, 2014. One hundred and fifteen wetland conservation projects have been completed in China. http://www.forestry.gov.cn/main/72/content-653065.html.

State Oceanic Administration, 2014. A review of the series of land reclamation III: Sea area utilization power marine ecological civilization construction. China Ocean News. http://www.soa.gov.cn/xw/dfdwdt/jgbm_155/201412/t20141203_34342.html.

Stone, K., Bhat, M., Bhatta, R., Mathews, A., 2008. Factors influencing community participation in mangroves restoration: A contingent valuation analysis. Ocean Coast. Manage. 51 (6), 476-484.

Sun, Z.G., Sun, W.G., Tong, C., Zeng, C.S., Yu, X., Mou, X.J., 2015. China's coastal wetlands: Conservation history, implementation efforts, existing issues and strategies 
for future improvement. Environ. Int. 79, 25-41.

Thom, R.M., 2000. Adaptive management of coastal ecosystem restoration projects. Ecol. Eng. 15 (3), 365-372.

Tong, S.Q., Song, N.Q., Yan, H.K., Fu, Q., 2014. Management measures and recommendations in improving the Bohai Sea environment over the last quarter century. Ocean Coast. Manage. 91, 80-87.

Walters, B.B., 1997. Human ecological questions for tropical restoration: Experiences from planting native upland trees and mangroves in the Philippines. For. Ecol. Manage. 99 (1-2), 275-290.

Wan, S., Qin, P., Liu, J., Zhou, H., 2009. The positive and negative effects of exotic Spartina alterniflora in China. Ecol. Eng. 35 (4), 444-452.

Wang, G., Qin, P., Wan, S.W., Zhou, W.Z., Zai, X.M., Yan, D.L., 2008. Ecological control and integral utilization of Spartina alterniflora. Ecol. Eng. 32 (3), 249-255.

Wang, K.Y., 2013. The Yangtze River estuary ecosystem restoration technology and decision management. Science Press, Beijing.

Wang, Q.Y., Zhuang, Z.M., Deng, J.Y., Ye, Y.M., 2006. Stock enhancement and translocation of the shrimp Penaeus chinensis in China. Fish. Res., 80(1), 67-79.

Wang, W.Q., Wang, M., 2007. The mangroves of China. Science, Beijing.

Waycott, M., Duarte, C.M., Carruthers, T.J., Orth, R.J., Dennison, W.C., Olyarnik, S., et al., 2009. Accelerating loss of seagrasses across the globe threatens coastal ecosystems. P. Natl. Acad. Sci. USA 106 (30), 12377-12381.

Williams, P., Faber, P., 2001. Salt marsh restoration experience in San Francisco Bay. J. Coast. Res. 27, 203-211.

Williams, P., Faber, P., 2004. Design guidelines for tidal wetland restoration in San Francisco Bay. The Bay Institute and California State Coastal Conservancy, Oakland, CA. pp. 
$1-16$.

Wolters, M., Garbutt, A., Bakker, J.P., 2005. Salt-marsh restoration: Evaluating the success of de-embankments in north-west Europe. Biol. Conserv. 123 (2), 249-268.

Xia, D.X., Wang, W.H., Wu, G.Q., Cui, J.R., Li, F.L., 1993. Coastal erosion in China. Acta Geographica Sinica 48 (5), 468-476.

Yang, D.T., Yang, C.Y., 2009. Detection of seagrass distribution changes from 1991 to 2006 in Xincun Bay, Hainan, with satellite remote sensing. Sensors 9 (2), 830-844.

Yang, L., 2007. Development of artificial reefs in China and suggestions. Fisheries Science \& Technology 2007 (3), 1-5.

Yang, S.L., Chen, J.Y., 1995. Coatal salt marshes and mangrove swamps in China. Chin. J. Oceanol. Limnol. 13 (4), 318-324.

Yang, W.B., Zhang, B., Li, J.L., Liu, Q., Chen, Y., Zhang, X.M., et al., 2011. A study on the current situation of artificial reef construction in China. Fishery Resources and Environment Branch in China Society of Fisheries.

Yu, D.P., Zou, R.L., Huang, H., 1996. A preliminary study on hermatypic coral transplantation on Luhuitou fringing reef, Sanya. The second national symposium on biodiversity conservation and sustainable utilization 205-209.

Zedler, J.B., 2000. Progress in wetland restoration ecology. Trends Ecol. Evol. 15 (10), 402-407.

Zedler, J.B., 2000. Handbook for restoring tidal wetlands. CRC press.

Zhang, G.Q., Chen, Y., Zhang, P.D., Tian, T., Liu, H.Y., Xu, C.C., 2003. Significance and feasibility of establishing marine ranching in Chinese sea area. Journal of Dalian Fisheries College 18(2), 141-14.

Zhejiang Bureau of Quality Technical Supervision, 2014. Technical Specification for Mangrove Afforestation. 
http://www.zjbts.gov.cn/HTML/2014122/gzdtbzh/2bd679fd09cf4a0a9a7bfec337aa4 d34.html.

Zheng, F.Y., Qiu, G.L., Fan, H.Q., Zhang, W., 2013. Diversity, distribution and conservation of Chinese seagrass species. Biodiversity Science 21(5), 517-526.

Zhou, T., Liu, S.C., Feng, Z.L., Liu, G., Gan, Q., Peng, S.L., 2015. Use of exotic plants to control Spartina alterniflora invasion and promote mangrove restoration. Sci. Rep. 5: 12980.

Zhuang, Z.Y., Cao, L.H., Li, B., Gao, W., 2011. An overview of beach nourishment in China. Marine Geology \& Quaternary Geology 31 (3), 133-139.

Zou, R.L., 2001. Fauna sinica: hermatypic coral. Science Press, Beijing, pp. 1-289.

Zuo, P., Zhao, S.H., Liu, C.A., Wang, C.H., Liang, Y.B., 2012. Distribution of Spartina spp. along China's coast. Ecol. Eng. 40, 160-166.

\section{FIGURE CAPTIONS}

Figure 1 Historical trends in China's coastal restoration. Shown is the number of coastal restoration projects (in total and for each major coastal ecosystem) conducted per year.

Figure 2 Spatial distributions of coastal restoration projects in China. (a) All coastal ecosystems, (b) tidal marsh, (c) mangrove, (d) seagrass, (e) coral reef, (f) sandy beach, and (g) coastal waters. The background color of each panel indicates ecosystem areas in province-level regions (darker areas for greater values). See Supplementary Information for data sources.

Figure 3 Degraded and restored coastal wetlands as percentages of China's total and their ecosystem services values. Data for other ecosystems were not available. Note that the ecosystem services values are context-dependent and can shift with economic and cultural 
development and also with ideological and political changes. The ecosystem services values presented here are the estimates of global averages currently available. See Supplementary Information for data sources.

Figure 4 Different types of sponsors in China's coastal restoration.

Figure 5 General framework of shifting paradigms in China's coastal restoration. 


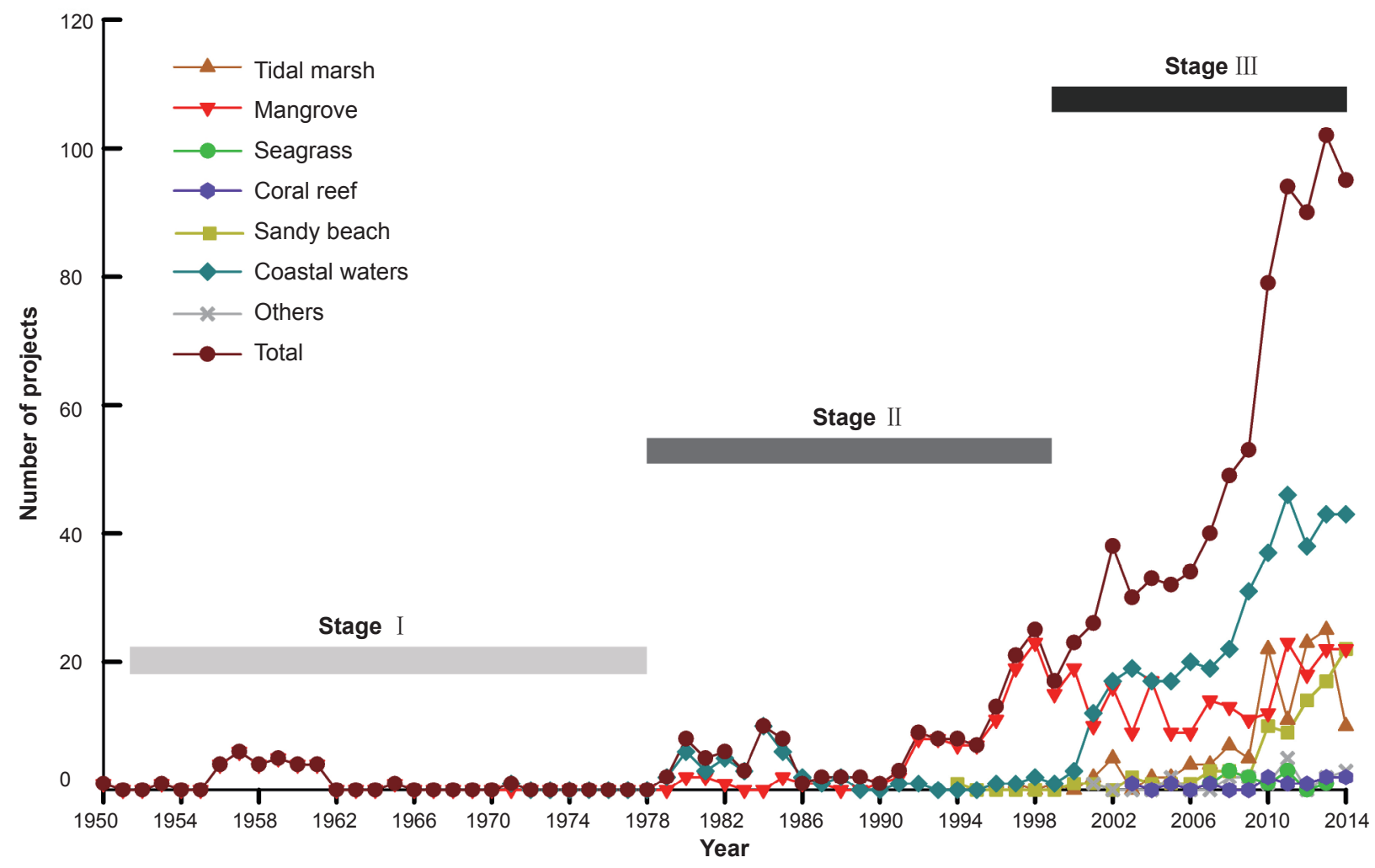


(a)<smiles>C1CC1N1CC1</smiles>

\section{Ecosystem Type}

$\Delta$ Tidal marsh

$\checkmark$ Mangrove

Seagrass

- Coral reef

- Sandy beach

Coastal waters

- Others

WIII Releasing region

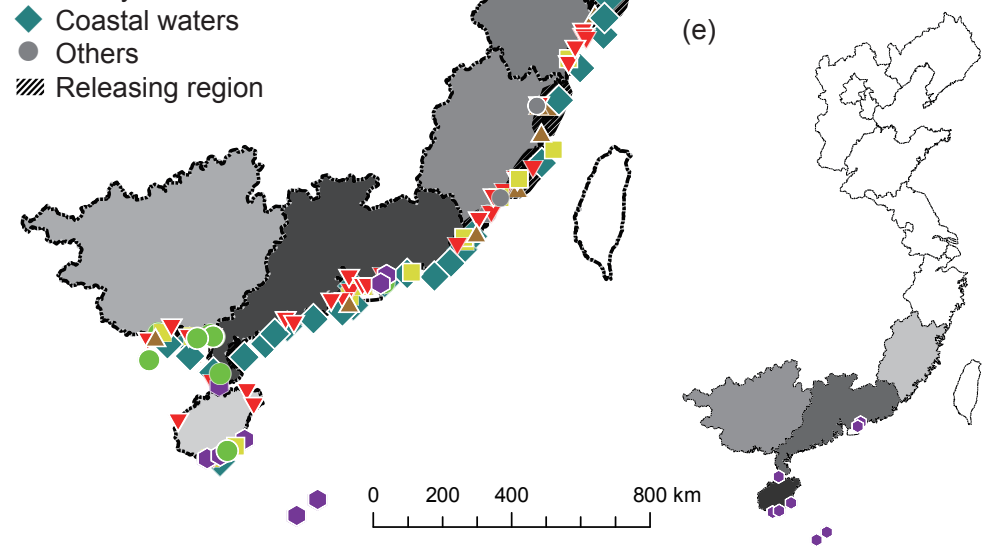

(b)

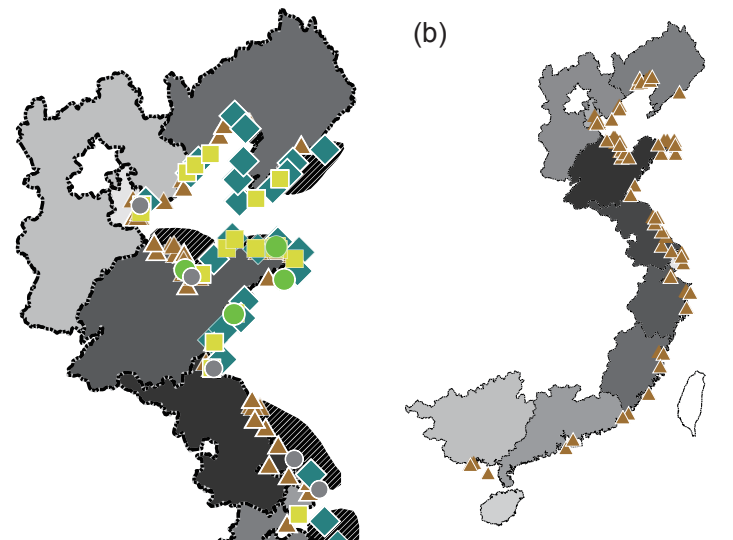

(e) (c)
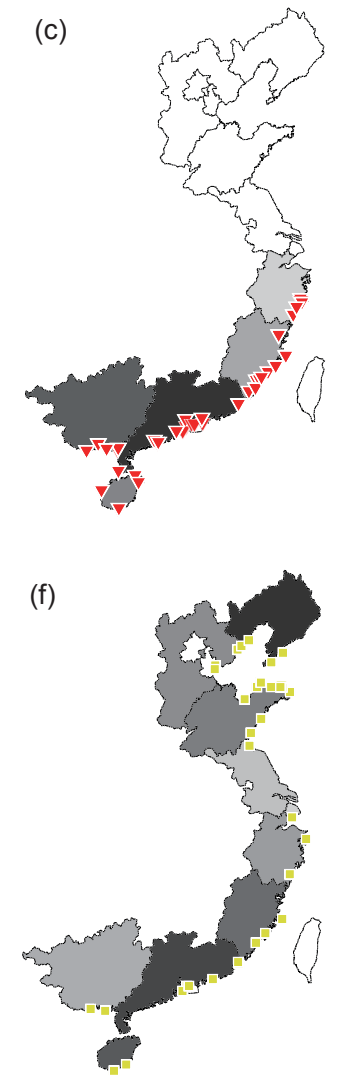

(d)

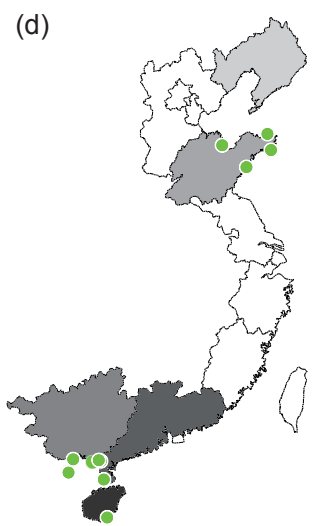

(g)

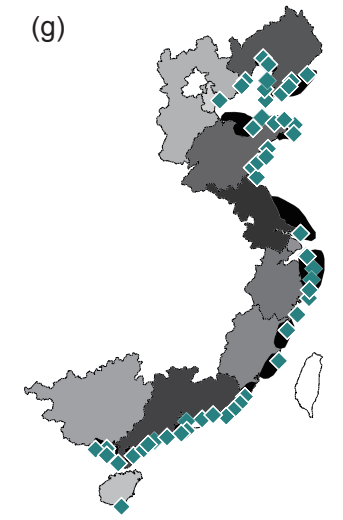




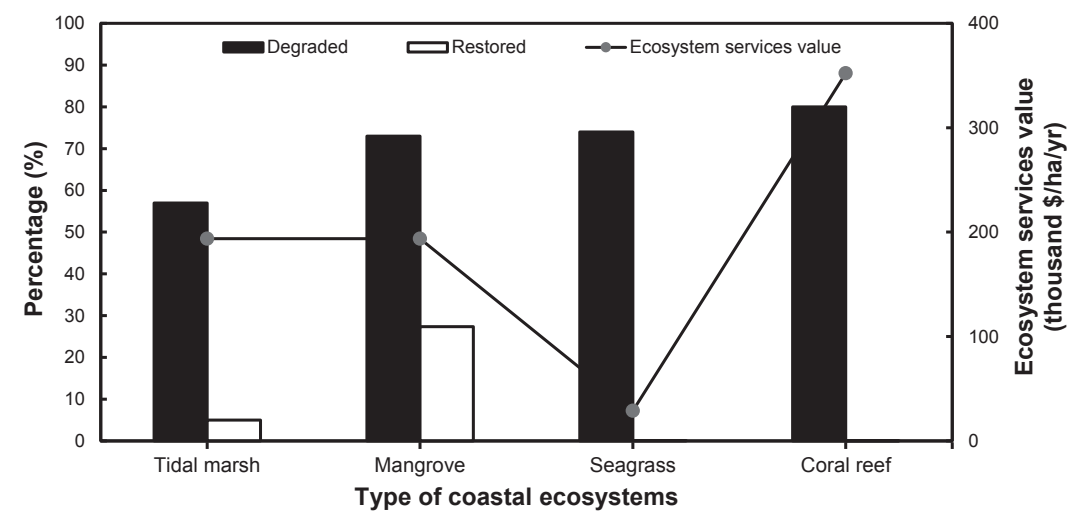




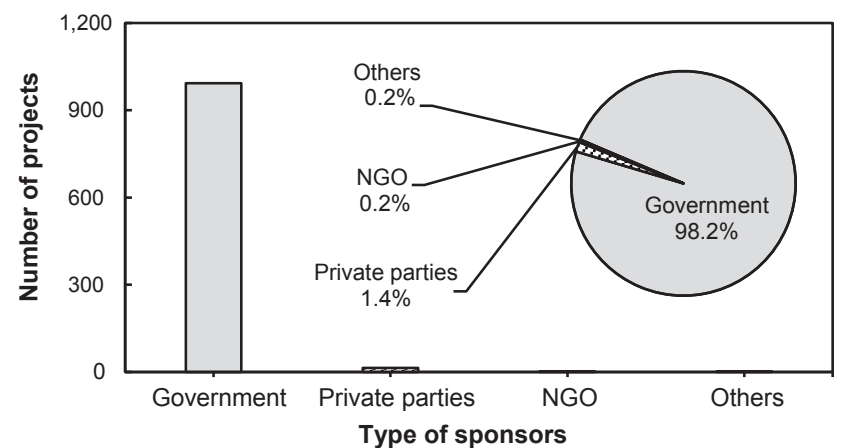


Current

Advanced

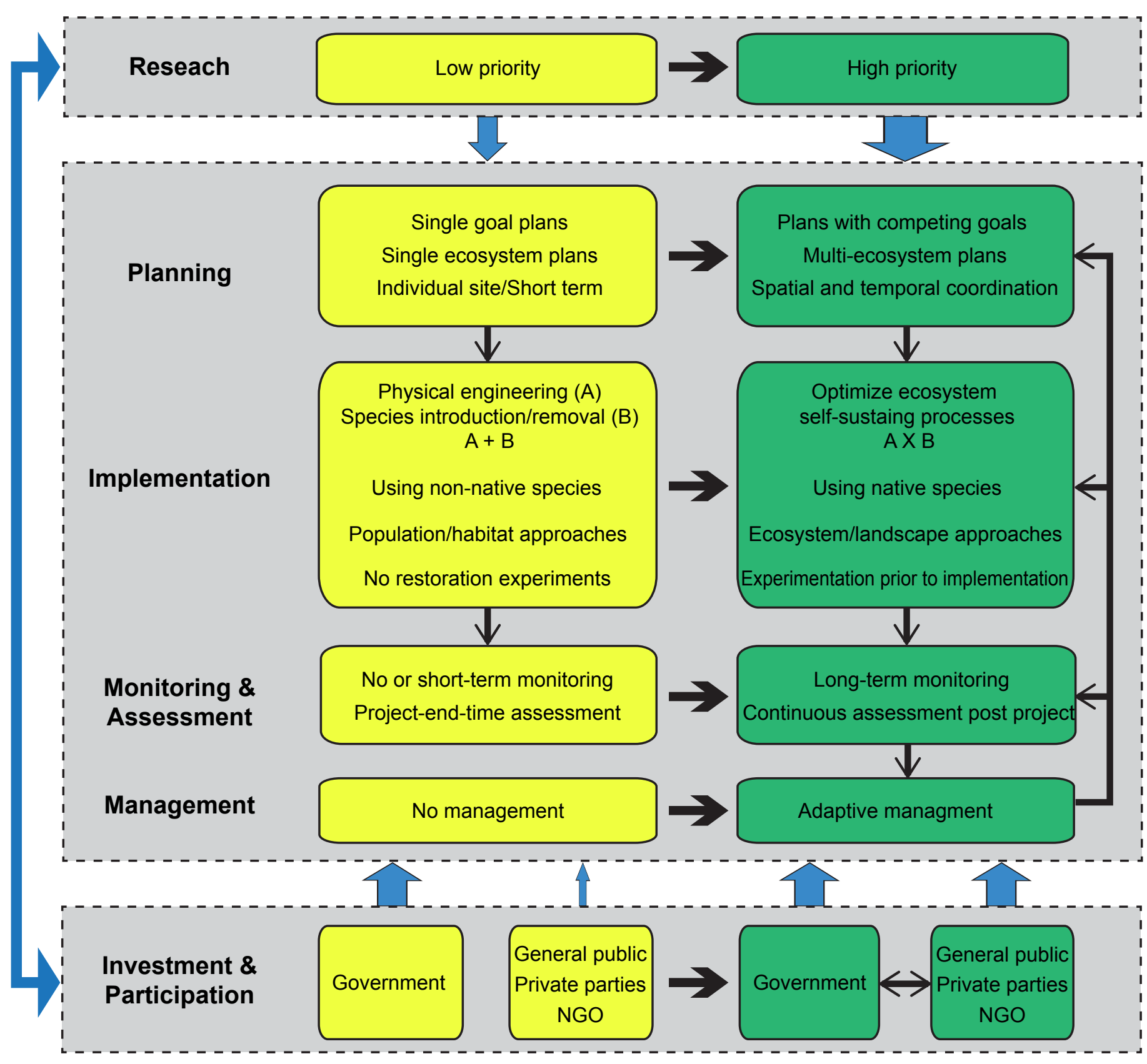



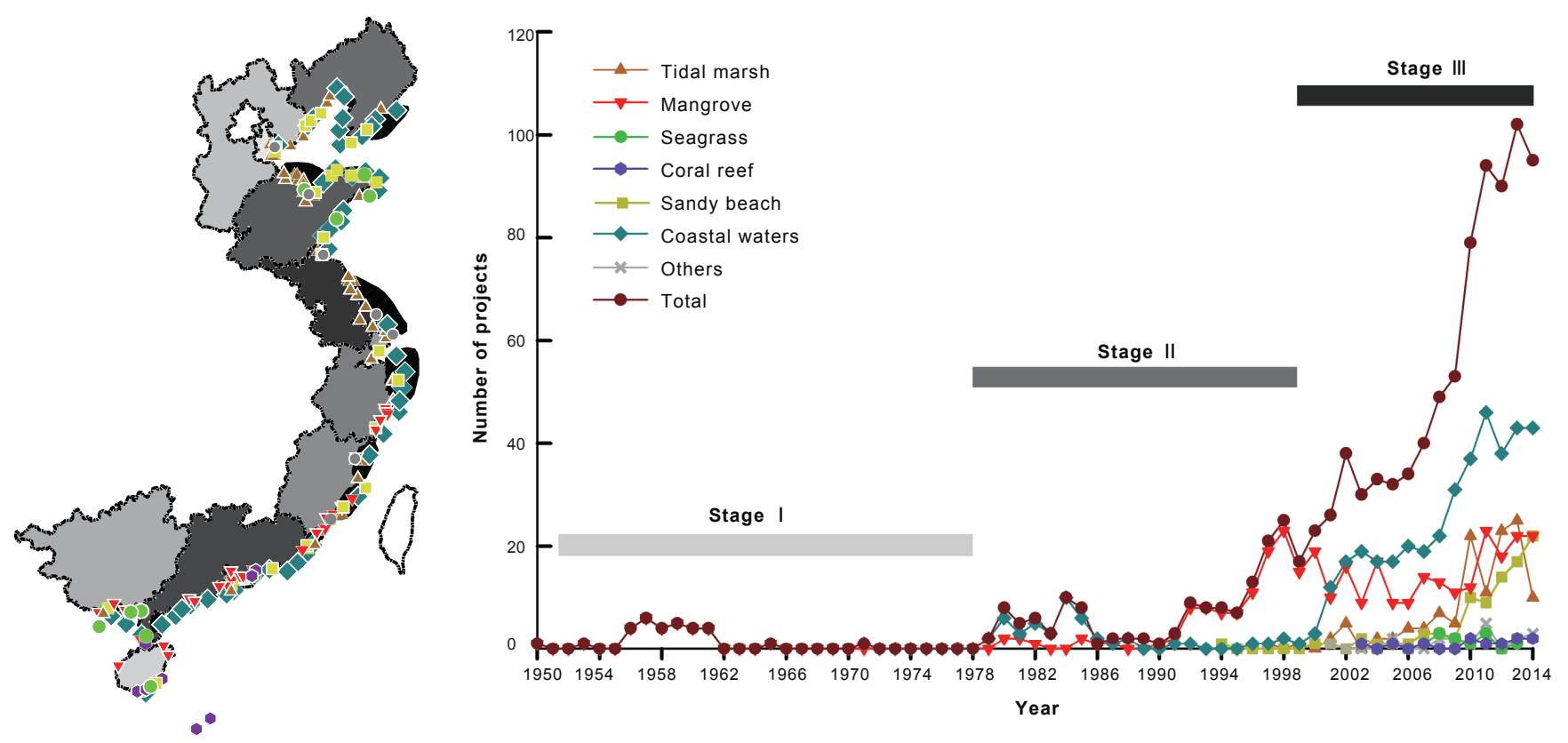